IZA DP No. 8039

Ethnic Disparities in the Transition to Home Ownership

Aslan Zorlu

Clara H. Mulder

Ruben van Gaalen

March 2014 


\title{
Ethnic Disparities in the Transition to Home Ownership
}

\author{
Aslan Zorlu \\ University of Amsterdam \\ and IZA \\ Clara H. Mulder \\ University of Groningen
}

Ruben van Gaalen

Statistics Netherlands (CBS)

Discussion Paper No. 8039

March 2014

IZA

P.O. Box 7240

53072 Bonn

Germany

Phone: +49-228-3894-0

Fax: +49-228-3894-180

E-mail: iza@iza.org

Any opinions expressed here are those of the author(s) and not those of IZA. Research published in this series may include views on policy, but the institute itself takes no institutional policy positions. The IZA research network is committed to the IZA Guiding Principles of Research Integrity.

The Institute for the Study of Labor (IZA) in Bonn is a local and virtual international research center and a place of communication between science, politics and business. IZA is an independent nonprofit organization supported by Deutsche Post Foundation. The center is associated with the University of Bonn and offers a stimulating research environment through its international network, workshops and conferences, data service, project support, research visits and doctoral program. IZA engages in (i) original and internationally competitive research in all fields of labor economics, (ii) development of policy concepts, and (iii) dissemination of research results and concepts to the interested public.

IZA Discussion Papers often represent preliminary work and are circulated to encourage discussion. Citation of such a paper should account for its provisional character. A revised version may be available directly from the author. 
IZA Discussion Paper No. 8039

March 2014

\section{ABSTRACT}

\section{Ethnic Disparities in the Transition to Home Ownership}

This paper examines ethnic disparities in the transition to home ownership using longitudinal register data from the Netherlands. The study performs a discrete duration model to account for individual and parental background and neighbourhood conditions. Subsequently, the size of explained variance in the home ownership gap between Dutch and ethnic minority groups is estimated using the Oaxaca-Fairlie non-linear decomposition method. The analysis indicates that the home ownership gap is the highest for Moroccans $(0.07)$ of which only 0.042 is explained by the observed characteristics. For Turkish residents, 0.043 of the total 0.046 gap is explained by their background characteristics. The estimated transition rate to home ownership for Surinamese migrants would have been slightly higher than for Dutch residents if they had the same characteristics as Dutch residents. Western migrants have the smallest gap (0.024), of which 0.021 is explained by their observed characteristics.

JEL Classification: R21

Keywords: immigrants, housing tenure, discrete time duration, non-linear decomposition

Corresponding author:

Aslan Zorlu

University of Amsterdam

Faculty of Social and Behavioural Sciences

Plantage Muidergracht 14

1018 TV Amsterdam

The Netherlands

E-mail: A.Zorlu@uva.nl 


\section{Introduction}

An increasing share of population in European countries is composed by immigrants and their descendants. In the housing markets of many countries, immigrants are predominantly tenants and less likely homeowners (Dawkins, 2005; Boehm and Schlottmann, 2009; Constant et al., 2009). This has possibly implications for the socioeconomic position of immigrants and their integration in the host society as well as housing market prospects. This study aims to quantify the homeownership gap for various ethnic groups with respect to Dutch and the effects of variables that are thought to determine homeownership. This paper contributes to the literature in three distinct ways. Firstly, we use unique register panel data of the entire Netherlands population and apply a new methodology to estimate the ethnic gap in homeownership. Secondly, we do estimate the transition to homeownership to identify more precise effects of a series of time-varying variables, rather than simply estimating homeownership probabilities. Thirdly, this study is also unique considering its focus on an European country outside of the US and new immigrant groups.

Home ownership is an important form of wealth accumulation and a central dimension of social well-being. Depending on the national context and housing-market circumstances, ownership tends to offer financial benefits in the form of tax deduction rules, inflation protection and asset appreciation. It is also linked to better physical and psychological health and greater life satisfaction, as well as improved educational, behavioural and social outcomes for children (Coulson and Dalton, 2010; Haurin et al., 2002;). In addition, home ownership is positively associated with neighbourhood amenities such as quality of schools, public services and space, and health. It encourages individuals to invest in local amenities and social capital and thereby improve their community (Coulson and Li, 2013; DiPasquale and Glaeser, 1999; Engelhardt et al., 2010).

Home ownership has been evidenced to be relatively low level for racial and ethnic minority groups in immigration countries. Most of previous research on racial and ethnic disparities in home ownership was conducted in the United States. A lot of studies focused on black-white home ownership differentials (Kain and Quigley, 1972; Gyourko and Linneman, 1996; Gyourko et al., 1999; Gabriel and Painter, 2003; Deng et al., 2003; Painter et al., 2001; Gabriel and Rosenthal, 2005; Hilber and Liu 2008). Later studies also examined home ownership differentials between immigrant groups (Hispanics and Asians) and whites (Alba and Logan, 1992; Krivo, 1995; Coulson, 1999; Painter et al., 2003, 2004; Yu, 2006; Wachter and Megbolugbe, 1992; Megbolugbe and Cho, 1996; Haurin and Rosenthal, 2009; Cortes et al., 2007; DeSilva and Elmelech 2012). These studies have established the existence of a significant disparity between whites and blacks and other ethnic groups, although there are disparities across the groups.

European research on ethnic home ownership gap is scarce and mainly limited to Germany. Constant et al., (2009) show that immigrants are significantly less likely to own their homes compared to natives. They suggest that home ownership levels of immigrants are positively correlated with a stronger commitment by immigrants with the host country, for a given set of socioeconomic and demographic characteristics, regardless of the degree of their home country orientation. Sinning (2010) confirms the relatively low level of home ownership among immigrant households and shows that immigrant home ownership does not increase with the duration of residence in Germany which would be expected from assimilation perspective.

In many European countries, immigrants and their descendants tend to be less likely to own a home and, instead, a disproportional number live in social housing in large cities (Whitehead and Scanlon, 2007). A large social housing sector may be a factor which explains why home ownership is less attractive. In the Netherlands, non-western immigrants are strongly concentrated in the social housing sector and, their home ownership level is significantly low. Financial constraints in combination with the affordability of social housing may be partially responsible for the low home ownership level. However, it is quite likely that other factors can potentially explain low home ownership among some ethnic minority groups, such as restrictions of access to other types of housing and mortgages, a strong home-country orientation of an ethnic group, different preferences 
for forms and location of investments, preferences for certain residential locations, and the availability of affordable housing in these locations and discrimination. Besides general benefits, home ownership has additional implications for migrants. Most importantly, migrants' home ownership is seen as a commitment to the host society and an important step toward assimilation into mainstream society (Alba and Logan, 1992; Myers and Lee, 1998). Ethnic disparities in home ownership are therefore a source of concern because home ownership is associated with prosperity and the transition to home ownership is seen as an indicator for improvement in the position of household. This study aims to provide empirical evidence for determinants of ethnic home ownership gap which will give a direction for policy interventions to increase home ownership rate among immigrants. In particular, the separate contributions of observed disadvantages in socioeconomic position of immigrants will be assessed and the size of unobserved differences for each immigrant group will be quantified.

Most studies which seek to explain ethnic and racial differentials in home ownership used cross-sectional data. Only a small number of studies used a dynamic analysis to quantify determinants of ethnic gap in home ownership (Dawkins 2005; Boehm and Schlottmann, 2009; Charles and Hurst, 2002). This paper builds on previous work by examining the transition to home ownership using longitudinal register data for the period between 1999 and 2005 for ethnic groups in the Netherlands. The use of longitudinal data allow us to isolate the relationship between a large number of explanatory variables and home ownership much more effectively than can be done with cross-sectional data for which endogeneity bias is likely to be a serious concern. This paper examines how individual socio-economic and demographic characteristics, parental background and neighbourhood characteristics contribute to ethnic gaps in transition to home ownership. First, we estimate home ownership transitions for separate ethnic groups using discrete time duration models and register data for entire population between $20-45$ years in the Netherlands. We then apply Oaxaca-type decomposition method (Fairlie, 1999, 2002) and an alternative decomposition to quantify the explained component of ethnic disparities in home ownership transitions. Finally, we perform robustness checks.

\section{Role of ethnicity in home ownership}

Relatively low home ownership rates among racial and ethnic minority groups have usually been ascribed to their weak socio-economic position. However, differences in home ownership levels for some minority groups can be only partly explained by differences in socio-economic characteristics. An unexplained residual is often attributed to unobserved factors, such as ethnic preferences and discrimination in the credit and housing markets (DeSilva and Elmelech 2012; Coulson and Dalton, 2010; Constant et al., 2009). This study aims both to delineate separate contributions of observed characteristics and to distinguish the contribution of unobserved factors which may be attributed to ethnicity such as ethnic preferences and discrimination. Since our administrative data include a large set of relevant observed variables, remaining unexplained differences in home ownership rates are likely attributable to ethnic background. We expect that this unexplained ethnicity component will be larger for low status ethnic minority groups that are at a relatively long distance from the Dutch population in terms of socio-economic, demographic and cultural characteristics (Kullberg et al. 2009).

Regarding observed characteristics, literature on ethnic and racial disparities in home ownership has generally considered a set of determinants which can be grouped into household socio-economic characteristics, institutional structure, ethnic group specific factors and ethnic residential segregation (Constant et al., 2009; Alba and Logan, 1992).

Household characteristics include primary determinants of home ownership such as household structure (marital status, children), demographic characteristics (gender, age) and human capital endowment of households (education, occupation, work experience) that are basic determinants of income generating power and an inclination to invest in housing. Immigrant families from non-western countries are in general relatively large in size and have a poor socio-economic 
status (Zorlu and Hartog 2012). These factors are likely to play an important role in the low prevalence of owner-occupied homes among immigrant families.

Another line of literature refers to a less favourable institutional structure in receiving countries for immigrant families that lack relevant 'qualifications' to move to an owner-occupied home. Formal regulations on mortgage markets may exclude immigrants with a relatively short duration of residence if these regulations rely on past household savings and proven income generating power as well as employment prospects. In addition, immigrants may have less knowledge of housing markets and a poor access to relevant information about home ownership. On top of these mismatches, implicit discrimination by mortgage providers and real estate agents can discourage potential homeowners among immigrants (Aalbers 2007). Mortgage providers, for example, may tend to evaluate an immigrant's income potential as lower than a native's even with similar underlying income and labour market position, and therefore assess the risk of providing a mortgage to an immigrant as higher.

Ethnic group specific factors refer to the degree of home and host country orientation of an ethnic group and familiarity with home ownership tradition in the home country. As far as immigrants are concerned, one's own home in the host country is often not the only option as regards improving one's life conditions and accumulating wealth. The immigrants may first prefer to own a home in their home country, depending on their attitude towards their home country. Constant et al. (2009) show that immigrants with a stronger commitment to the host country are more likely to become a homeowner, regardless of their level of attachment to their home country. Immigrants' orientation toward their host country is strongly related to the duration of stay and their intention to stay in the host country. Although the degree of commitment to the host country is not necessarily influenced by attachment to home country, the balance between home and host country orientation can still affect the location of investment in housing. The balance can change over time as a result of positive and negative developments in home and host countries. For instance, negative attitudes against immigrants in the host country and rising (economic) opportunities in the home country can create incentives to buy a house in the home country, instead of buying a house in the host country. By contrast, the given situation in the host country and unfavourable socio-economic conditions in the home country can encourage immigrants to develop a stronger commitment to the host country.

Immigrants who either aim to return to, or spend more time in, the home country might prefer to own a house in the home country rather than in the host country. The home-country orientation of immigrants may also be triggered either by attitudes towards immigrants in the host country, or by developments in the host country. More recent studies have emphasized the role of solidarity within extended-family in explaining differences in home ownership (Charles and Hurst, 2002; Hall and Crowder, 2011). The implication of these studies is that families rely not only on their own economic resources, but also on those of non-household members to secure more desirable residential arrangements.

In the host country, immigrants are often concentrated in a few neighbourhoods of large cities. This outcome was initially driven by affordable housing and employment opportunities and strengthened by emerging ethnic enclaves with ethnic goods and services with new immigrants being able to count on the solidarity of co-ethnics. Many immigrants continue to reside in immigrant neighbourhoods which they are reluctant to leave. Typically, these immigrant neighbourhoods have a low share of owner-occupied homes. If immigrants were to have specific location preferences in favour of immigrant neighbourhoods, they would have difficulty finding owner-occupied homes.

For a given set of socio-demographic characteristics of individuals, the probability of owning a home is also influenced by macroeconomic and housing market conditions such as interest rates, economic performance, property prices, rent levels, construction of affordable homes, etc. This type of macro-level effect can be better understood when the transition to home ownership is examined for a determined time interval. This is one of the advantages of longitudinal analysis. Cross-sectional analysis generates home ownership probabilities that are cumulative in time and which can result 
from a variety of factors that trigger home ownership. This study examines the transition to home ownership for people aged between 20 and 45 who are in a lifecycle stage which is most likely to include becoming a homeowner. This dynamic analysis allows us to separate macro-level effects from individual and contextual variables.

\section{Migrants in the Netherlands}

The ethnic composition of the Dutch population has changed significantly owing to immigration flows which followed the Second World War. The largest migrant groups in the Netherlands are Turks, Moroccans and Surinamese. Immigration flows from Surinam were the result of the colonial relationship with the Netherlands and intensified after the decolonization of Surinam in 1975. The first Turks and Moroccans came to the Netherlands as guest workers in the 1960s, and flows from these countries were reinforced by family re-unification and family formation. In addition to these groups, we categorize migrants from developed countries as western migrants. This group can act as an interesting reference for other non-western migrant groups. Immigration from Western countries has been related to economic conditions.

This historical background reflects the socio-economic position of these groups and their cultural distance from the host society. Surinamese migrants often speak Dutch and adopt cultural norms similar to those of the Dutch through their colonial relations. Their labour-market position is somewhat less favourable than that of native Dutch. By contrast, the predominantly Muslim Turkish and Moroccan migrants are frequently less well educated, hardly ever speak Dutch prior to immigration, and are at a greater cultural distance from the Dutch. There is empirical evidence that these migrants face significant difficulties in the Dutch education system, labour and housing markets. They are frequently unemployed and are concentrated at the bottom of the occupational distribution (Zorlu and Hartog 2012; Zorlu 2013). Although the migration histories of Turkish and Moroccan migrants are similar, there are still significant differences between these groups. The most relevant difference is a strong orientation of Turkish immigrants towards their own group and their home country. The Moroccan community is known to be more fragmented and their relationships with Morocco is relatively weak. The home country orientation of Turkish immigrants might have even increased in the last decade since the Turkish economy has started to flourish and many (second generation) Turkish migrants have migrated to Turkey for work (CBS 2005). In addition, there is some evidence that banks are reluctant to grant mortgages to ethnic minorities (Aalbers 2007). Western migrants are in many respects similar to the native Dutch, and their labour-market position is favourable (Zorlu and Hartog 2012).

Based on the background of these migrant communities, we could expect Turkish and Moroccan immigrants, who are at a relatively long distance from the Dutch population in terms of socio-economic, demographic and cultural characteristics, to have the lowest transition rate to home ownership. We also expect that after controlling for observed characteristics, a significant part of ethnic gap in home ownership 
home ownership. We were able to observe transitions to home ownership for the entire population for the period 1999-2005. In accordance with the spirit of this study, we selected individuals who were living in rented accommodation in 1999 and followed them over time to identify transitions to home ownership. We excluded people who were living with their parents because, if young adults share an owner-occupied home with their parent(s), the data is unclear as to who owns the home, the parent(s) or the adult child. The SSD contains a variety of variables measuring individual sociodemographic and socio-economic position and geographic mobility. The measurement moment is the last Friday of September of each year. The data was taken from the population register and therefore contains information on every legal inhabitant of the Netherlands. The follow-up through the years is based on a unique registration number and is completed as long as people remain registered in the Netherlands.

In order to allow a regression analysis to be conducted within available technical capacity, we drew a 3 per cent sample of the native Dutch population and a 25 percent sample of Western migrants. We also used the entire population of Turkish, Moroccan and Surinamese migrants. Since we were conducting a discrete-time duration analysis, the data was restructured as person-year data, in which an individual occurs a maximum of six times when this individual still lives in rented accommodation at the end of the period of analysis (in 2005). In the case of home ownership in 1999, this individual does not occur in the risk set.

Figure 1 shows ethnic disparities in percentages of residents aged 20-45 living in owneroccupied homes in 1999 and 2005. The home ownership rate is much lower for migrant groups, in particular for non-western migrants. Moroccans are least likely home owners, they are followed by Antillean, Turkish and Surinamese migrants. The increase in the home ownership rate between 1999 and 2005 is relatively high for Turkish and Surinamese migrants.

Figure 1. Percentages of residents aged 20-45 in owner-occupied homes in 1999 and 2005

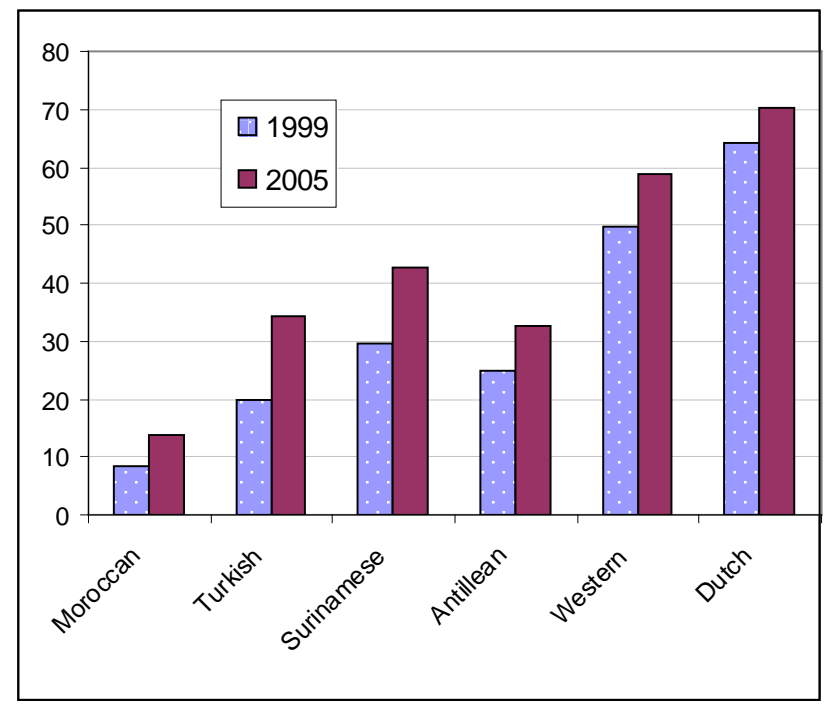

Although transitions to home ownership can, in principle, be made by people who stay in the same dwelling - for example by people who buy their rented accommodation - we were unable to use such transitions because the changes in the tenure of a particular dwelling between years were sometimes no more than administrative corrections, and it was impossible to detect for which transitions this was the case. Transitions to home ownership were therefore only taken into account if a move took place.

To measure ethnic differences in the transition to home ownership, we used a large number of explanatory variables that were available in the data. Ethnicity was measured using the official definition of Statistics Netherlands, namely 'someone is considered to be of non-Dutch origin when at least one parent was born abroad'. Those of migrant origin who were themselves also born abroad 
were categorized as first generation, and those who were born in the Netherlands were categorised as second generation. Level of education was measured using a completed education variable which was constructed by Statistics Netherlands from registers and surveys. This variable covers about onethird of the population and the remaining part of population has missing values. It is the best available variable to measure education level. Predicting missing values for this very important variable can be problematic but we check the effects of using this-incomplete education variable on estimates, such as using only the sample with information for education and alternatively excluding education variable. Finally, we decided to use all observations controlling for missing values. A dummy control variable is used for missing values in the regression analysis (parameter not shown). With regard to labour market position, we were able to distinguish receivers of benefits (unemployment, disability or social welfare benefits) from those earning income from labour (reference category). Those who did not earn income from labour nor received benefits (e.g. housewives) were coded as having an 'other labour market position'. Earning data was obtained from the tax register and is available only for individuals in employment. Because some individuals do not have a paid-job, this variable includes missing values. We use a dummy control variable for missing values to keep all observations in the analysis. Characteristics of the parents were retrieved using record linkage between the young adults' and their registered parents' data. 'Father/mother absent' refers to cases in which record linkage was unsuccessful. This was the case when the parents had died or were living abroad. The value of an individual's home was measured through the property's so-called WOZ value. The WOZ value is used as a base for property tax. It is determined by the municipalities and is supposed to reflect the market value of a property. It has some missing values (7\%), mainly for newly constructed homes. Cases with missing values were included in the analysis and controlled by a dummy variable. In the variable that measures partnership status, we measured the actual partnership status before a potential transition to home-ownership, and also distinguished those making a transition from single to couple from steady singles to acknowledge the importance of partnership transitions to the transition to home-ownership (compare Mulder and Wagner 1998). Neighbourhood conditions were measured at the level of four-digit postal code areas $(\mathrm{N}=11000$ areas) and refer to the population composition of the neighbourhood and housingmarket conditions. The share of rental versus owner-occupied homes in the housing stock, for example, shows substantial spatial variation (e.g. between urban and rural areas), and this variation is captured with a neighbourhood-level variable measuring the percentage of rental homes. Table 1 displays the mean values of variables at exit or right censoring by ethnic group.

It is immediately apparent that Moroccan and Turkish migrants have more distinct sociodemographic and economic characteristics. The proportion of women and second generation migrants is significantly lower than Surinamese and Western migrants. Their households are usually composed of married couples with children. In addition, they have a low level of education and their socio-economic position is lower in terms of lower labour market participation, earnings and higher dependency on benefits. Their parents are less likely to be homeowners. They are clustered in neighbourhoods with a high concentration of non-western immigrants and benefit-receivers and with a high concentration of rented and low-value accommodation. Surinamese migrants score better on the socio-economic indicators compared to Moroccan and Turkish migrants, and their family structure differs from that of Mediterranean migrants. In Surinamese households, the position of women is much stronger and there are more single-parent households. Characteristics of Western migrants are quite similar to the characteristics of Dutch.

Table 1. Means of independent variables at exit or right censoring

\begin{tabular}{lrrrrr}
\hline & Moroccan & Turkish & Surinamese & Western & Dutch \\
\hline Individual characteristics & & & & & \\
\hline Age & 35.073 & 34.980 & 36.191 & 35.884 & 34.943 \\
Woman & 0.472 & 0.483 & 0.542 & 0.507 & 0.487 \\
Second generation & 0.093 & 0.129 & 0.183 & 0.574 & \\
\hline
\end{tabular}




\begin{tabular}{lrrrrr}
\hline Years since migration & 15.964 & 16.023 & 17.202 & 5.876 & \\
Education -primary or less (ref. \#) & 0.096 & 0.139 & 0.034 & 0.023 & 0.020 \\
Education -Extended primary & 0.162 & 0.167 & 0.125 & 0.076 & 0.063 \\
Education -Secondary & 0.449 & 0.431 & 0.493 & 0.423 & 0.369 \\
Education -High & 0.293 & 0.263 & 0.347 & 0.478 & 0.549 \\
Number of children in household & 1.905 & 1.623 & 1.031 & 0.828 & 0.908 \\
Benefit receiver & 0.330 & 0.321 & 0.229 & 0.153 & 0.127 \\
Other labour market position & 0.205 & 0.169 & 0.109 & 0.173 & 0.099 \\
Log earnings & 5.771 & 6.012 & 6.693 & 6.253 & 6.836 \\
Value of home (€ 10,000s) & 8.402 & 8.043 & 8.200 & 10.380 & 11.084 \\
Married / cohabiting (ref. single) & 0.702 & 0.759 & 0.245 & 0.340 & 0.331 \\
Separated / divorced & 0.100 & 0.122 & 0.226 & 0.119 & 0.091 \\
Single to Couple & 0.018 & 0.013 & 0.014 & 0.018 & 0.021 \\
\hline Parental background & & & & & \\
\hline Mother unmarried & 0.075 & 0.085 & 0.389 & 0.228 & 0.247 \\
Mother benefit receiver & 0.232 & 0.221 & 0.255 & 0.118 & 0.116 \\
Father benefit receiver & 0.305 & 0.281 & 0.136 & 0.097 & 0.127 \\
Father absent & 0.490 & 0.549 & 0.379 & 0.398 & 0.111 \\
Mother absent & 0.500 & 0.567 & 0.605 & 0.518 & 0.230 \\
Parent(s) owner of home & 0.019 & 0.048 & 0.129 & 0.241 & 0.451 \\
\hline Neighbourhood conditions & & & & & \\
\hline \% non-western migrants & 33.273 & 32.929 & 35.625 & 15.449 & 11.259 \\
\% rental homes & 72.911 & 72.374 & 73.377 & 59.555 & 52.675 \\
Average value of homes & 89.098 & 83.723 & 84.251 & 104.808 & 111.879 \\
\% benefit receivers & 15.676 & 16.187 & 15.494 & 12.799 & 11.725 \\
& & & & & \\
N & 98259 & 112057 & 100051 & 69146 & 59914 \\
\hline
\end{tabular}

\section{Econometric model}

Our unique data provided a rare opportunity to study the dynamic process of the transition to home ownership among various ethnic groups. The dynamic analysis assumed an underlying distribution of transition to home ownership over time which may reflect ethnic differences in preferences for home ownership.

We modelled individual transition to home ownership using a discrete-time duration model. The process time for being at risk of becoming a homeowner is assumed to start in 1999, and to end when an individual experiences a transition to home ownership. The calendar year 1999 is not a natural starting point for being at risk of a transition to home ownership. If strictly interpreted, the risk period should start at the moment the person leaves the parental home, or at some age at which young people can be considered as beginning to be at risk of becoming homeowners. It would also be preferable to confine the risk to those who have not been homeowners before (compare Mulder \& Wagner, 1998). This is not possible with the data at hand. This study therefore considers all people aged between 20-45 years who have left the parental home to be at risk from 1999 onwards. This implies the use of left-censored data and the possibility that, for some older people, their transition to home ownership is not their first. To deal with these problems, we assume that the risk of a transition depends on age and calendar time rather than duration, and control for calendar year and age. In addition, we perform robustness checks using the age group 23-27 years for whom the transition to home ownership is most likely to be their first transition experience. By choosing this strategy, we aim to avoid information loss and assess the transition rate of a large group of people who do not live in owner-occupied homes but who may potentially transit to home ownership. 
People who had not moved to an owner-occupied home in 2005 are right censored. Repeated spells are not considered.

The duration of stay in a rental home, $T$, is assumed to be a discrete random variable which takes on positive integer values only. We observe a total of $n$ independent individuals $(i=1,2, \ldots, n)$. The population at risk is in a rental home in the year 1999, which is the starting point, with time $T=0$. Each observation continues until time $t$, at which point an event occurs or the observation is censored in 2005. A rental home spell can end, $T=t$, in the state of home ownership. In each year, a person can either stay in a rental home or move to home ownership.

For the $i$-th person, the hazard rate of transition to home ownership in spell $k$ in period $t$, $h_{i}(t)$, is the conditional probability of a transition to home ownership in this interval $t$, given that it has not already occurred; $h_{i}(t)=\operatorname{Pr}\left(T_{i}=t_{i} \mid T_{i} \geq t_{i}-1, x_{i}(t)\right)$.

This hazard rate is thought to depend on the observed vector of explanatory variables that are categorized as fixed characteristics of the person such as age, gender, ethnicity, $X_{i}$, as personspecific and parental time varying variables such as education level, marital status and labour market characteristics of the person, the marital status of mother and labour market characteristics of both parents, $Z_{i t}$, and, as time varying neighbourhood characteristics such as median value of houses, the proportion of non-western migrants, owner-occupied homes and benefit receivers in the neighbourhood, $N_{i t}$.

$$
\ln \left(h_{i t} /\left(1-h_{i t}\right)\right)=\alpha_{t}+\beta X_{i}+\gamma Z_{i t}+\delta N_{i t}
$$

where $\beta, \gamma$ and $\delta$ are the vectors of corresponding parameters to be estimated, and $\alpha_{t}$ describes the variation in the baseline hazard and captures the variation in the hazard through time. We specify the baseline hazard as a piece-wise constant, the most flexible form, by specifying annual dummies. The piecewise constant baseline hazard function shifts with the characteristics of the person and his/her parental background and neighbourhood characteristics.

First, we estimate the ethnic gap in the transition to home ownership assuming that the transition process starts with the observation period in the current study. Subsequently, we perform robustness checks for the validity of this assumption. This involves, firstly, an estimation of the ethnic home ownership gap using cross-sectional data in 1999, rather than using the person-period data. In addition, we estimate a model for those aged 23-27 (see above).

The parameters are estimated by maximum likelihood using discrete time method, as suggested by Allison (1982). There may be persistent differences in transition hazards that are not accounted for by the observed variables. Failing to control for such unobserved heterogeneity can produce spurious duration dependence in the baseline hazard and also create biased estimates of parameters even if the unobserved characteristics are uncorrelated with the observed characteristics (Lancaster 1990, chapters 4 and 8). To deal with this problem, we incorporated residual heterogeneity into the model and estimated random effects logit models. Our estimations of logit models with unobserved heterogeneity component indicated that the parameter estimates do not suffer from heterogeneity biases. Our specification of baseline hazard is apparently sufficiently flexible to capture unobserved heterogeneity. Therefore, we present the estimates obtained from models without unobserved heterogeneity component.

Another sort of biases can arise if our observed variables would be subject to measurement error. Because our data come from registers, we do not expect measurement error caused by recall bias, misreporting or partial non-response. The variables, however, represent a registered 'reality' which is not necessarily true reality. If some individuals are involved in informal economic activities, the economic status of these people will be underestimated. In the highly regulated Dutch society, we do not have a good reason to believe that measurement error of observed variables will be influential and vary across ethnic groups. Therefore, the potential impact of measurement error is likely limited. In the absence of unobserved individual heterogeneity and substantial measurement error, our decomposition of ethnic disparities into an explained endowment part and an unexplained 
ethnicity component will reflect a good account for ethnic differences, conditional on their observed background variables.

We estimated discrete time hazard models for the ethnic origins separately: Dutch, Moroccan, Turkish, Surinamese and Western. We also estimated a model for the pooled sample in which migrant origin is an independent variable. This last model provides simple estimates of the ethnic gap relative to Dutch, given the observed background variables. The results are reported in Table 2. Even though some of the data was not derived from a sample, but from a complete population, we still take account of significance levels. We believe this makes sense because the data can be regarded as a one-moment sample from a theoretical population of many time points.

\subsection{Estimation results}

The parameter estimates for the separate ethnic groups indicate that a strong socio-economic position creates the hazard of transition to home ownership for all ethnic groups. Three variables, in particular, are associated with a strong socio-economic position: higher education and earnings, and parental home ownership. These variables have a significant positive effect on the hazard of transition to home ownership. The impact of higher education and parental home ownership is the largest for Moroccans and Turks. A weak socio-economic position is particularly associated with nonemployment, specified as dependence on social benefits and not participating in the labour market. Being not-employed significantly lowers the hazard rate for home ownership as expected. A higher number of children decreases the hazard rate of home ownership, possibly as a result of financial constraints due to higher costs of living for households with more children.

In line with the higher prediction of classical assimilation theory, second generation Moroccans and, to a lesser extent, second generation Turks have a higher hazard rate of transition to home ownership than their parents. However, the same does not apply to Surinamese. The hazard of home ownership is estimated to be lower for second generation than for the first generation Surinamese.

The last column in Table 2 gives the estimates of a model obtained from the pooled population. The estimation of this pooled model is an attempt to show ethnic differences in the hazard of transition. The odds ratios for ethnic minority groups give the ethnic gap relative to Dutch, holding observed characteristics constant. The odds ratio is the lowest for Moroccans who have a drastically lower hazard rate than Dutch. In addition, Antilleans, Turks and Western have a significant ethnic gap although this gap is very low for Western migrants. Strikingly, Surinamese have a higher hazard rate than Dutch if differences in characteristics are taken into account.

Table 2. Discrete time hazard model of the transition to home ownership with logistic distribution: baseline hazard t1-t6 and hazard ratios

\begin{tabular}{|c|c|c|c|c|c|c|}
\hline & Dutch & Moroccan & Turkish & Surinam & Western & All \\
\hline $\mathrm{t} 1$ & $0.015 * * *$ & $0.001 * * *$ & $0.007 * * *$ & $0.023 * * *$ & $0.017 * * *$ & $0.020 * * *$ \\
\hline t2 & $0.014 * * *$ & $0.001 * * *$ & $0.007 * * *$ & $0.022 * * *$ & $0.015 * * *$ & $0.019 * * *$ \\
\hline t3 & $0.014 * * *$ & $0.001 * * *$ & $0.007 * * *$ & $0.023 * * *$ & $0.015 * * *$ & $0.019 * * *$ \\
\hline t4 & $0.013 * * *$ & $0.001 * * *$ & $0.007 * * *$ & $0.020 * * *$ & $0.013 * * *$ & $0.017 * * *$ \\
\hline t5 & $0.014 * * *$ & $0.001 * * *$ & $0.007 * * *$ & $0.019 * * *$ & $0.014 * * *$ & $0.017 * * *$ \\
\hline t6 & $0.019 * * *$ & $0.001 * * *$ & $0.008 * * *$ & $0.023 * * *$ & $0.018 * * *$ & $0.021 * * *$ \\
\hline \multicolumn{7}{|l|}{ Individual characteristics } \\
\hline Age & 0.984 & $1.149 * * *$ & $1.078 * * *$ & 1.015 & 0.989 & 1.009 \\
\hline Age Squared & $0.999 * * *$ & $0.997 * * *$ & $0.998 * * *$ & $0.999 * * *$ & $0.999 * * *$ & $0.999 * * *$ \\
\hline Woman & $1.090 * * *$ & 0.981 & $1.088 * * *$ & $0.863 * * *$ & $1.086 * * *$ & $0.973 * * *$ \\
\hline Second generation & & $2.105 * * *$ & $1.158 * * *$ & $0.732 * * *$ & 1.018 & $1.080 * * *$ \\
\hline Years since migration & & $1.020 * * *$ & 1.003 & $0.992 * * *$ & 0.998 & $1.004 * * *$ \\
\hline Education -primary or less (ref.) & & & & & & \\
\hline
\end{tabular}




\begin{tabular}{|c|c|c|c|c|c|c|}
\hline Education - Extended primary & 1.202 & $1.397 *$ & 1.167 & 0.986 & 1.231 & $1.133 *$ \\
\hline Education-Secondary & $1.598 * * *$ & $1.816 * * *$ & $1.451 * * *$ & $1.344 * *$ & $1.564 * * *$ & $1.499 * * *$ \\
\hline Education -High & $1.865 * * *$ & $2.608 * * *$ & $1.985 * * *$ & $1.780 * * *$ & $1.824 * * *$ & $1.855 * * *$ \\
\hline Number of children in household & $1.047^{* * *}$ & $0.844 * * *$ & $0.885 * * *$ & $0.930 * * *$ & $0.965 * * *$ & $0.930 * * *$ \\
\hline \multicolumn{7}{|l|}{ Employed (reference) } \\
\hline Benefit receiver & $0.391 * * *$ & $0.404 * * *$ & $0.380 * * *$ & $0.380 * * *$ & $0.391 * * *$ & $0.389 * * *$ \\
\hline Other labour market position & $0.853 * * *$ & $0.791 * * *$ & $0.761 * * *$ & $0.891 * *$ & $0.863 * * *$ & $0.810 * * *$ \\
\hline Log earnings & $1.610 * * *$ & $1.491 * * *$ & $1.477 * * *$ & $1.571 * * *$ & $1.556 * * *$ & $1.497 * * *$ \\
\hline Value of home & $1.001 *$ & $1.010 * *$ & 0.992 & 1.000 & $1.001 * * *$ & $1.001 *$ \\
\hline \multicolumn{7}{|l|}{ Single (reference) } \\
\hline Married / cohabiting & $0.852 * * *$ & $0.829 * * *$ & $1.084 * * *$ & $1.829 * * *$ & $1.198 * * *$ & $1.203 * * *$ \\
\hline Separated / divorced & $1.462 * * *$ & 0.911 & $0.896 * * *$ & $1.221 * * *$ & $1.337 * * *$ & $1.196 * * *$ \\
\hline Single to Couple & $1.856 * * *$ & $1.166 *$ & 1.040 & $1.178 * *$ & $1.436 * * *$ & $1.296 * * *$ \\
\hline \multicolumn{7}{|l|}{ Parental background } \\
\hline Mother unmarried & $0.833 * * *$ & 0.943 & 0.957 & $0.862 * * *$ & $0.885 * * *$ & $0.866 * * *$ \\
\hline Mother benefit receiver & $0.928 * *$ & 0.944 & 1.033 & 0.978 & $0.947 *$ & 0.982 \\
\hline Father benefit receiver & $0.938 * *$ & $0.908 * *$ & $0.920 * * *$ & $1.054 *$ & 0.954 & $0.942 * * *$ \\
\hline Father absent & $0.901 * * *$ & 1.051 & 0.968 & $0.888 * * *$ & $0.946 *$ & $0.962 * *$ \\
\hline Mother absent & $1.144 * * *$ & $1.112 *$ & $1.104 * * *$ & 0.970 & 1.026 & $1.039 * * *$ \\
\hline \multicolumn{7}{|l|}{ Neighbourhood conditions } \\
\hline$\%$ non-western migrants & 0.999 & $0.992 * * *$ & $0.996 *$ & 1.002 & 0.998 & 0.999 \\
\hline$\%$ rental homes & $0.990 * * *$ & $0.983 * * *$ & $0.987 * * *$ & $0.987 * * *$ & $0.991 * * *$ & $0.987 * * *$ \\
\hline Value of home & $0.999 * * *$ & $0.993 * * *$ & $0.994 * * *$ & $0.994 * * *$ & $0.998 * * *$ & $0.997 * * *$ \\
\hline $\begin{array}{c}\text { \% benefit receivers } \\
\text { Ethnic origin }\end{array}$ & $1.006 * *$ & $1.023 * * *$ & $1.016 * *$ & 0.997 & 0.999 & $1.009 * * *$ \\
\hline Turkish & & & & & & $0.830 * * *$ \\
\hline Moroccan & & & & & & $0.363 * * *$ \\
\hline Surinamese & & & & & & 1.004 \\
\hline Antillean & & & & & & $0.709 * * *$ \\
\hline Western & & & & & & $0.885 * * *$ \\
\hline Missing -earnings & $24.78 * * *$ & $14.77 * * *$ & $11.94 * * *$ & $20.92 * * *$ & $16.97 * * *$ & $14.13 * * *$ \\
\hline Missing - education & $1.43 * * *$ & $1.31 *$ & $1.21 * * *$ & 1.09 & $1.37^{* *}$ & $1.26 * * *$ \\
\hline Missing - Value of home & $0.93 * * *$ & $1.29 * * *$ & 0.90 & 0.97 & 0.95 & 0.96 \\
\hline Missing - neighbourhood conditions & $0.92 * * *$ & $0.38 * * *$ & $0.50 * * *$ & $0.50 * * *$ & $0.81 * * *$ & $0.75^{* * *}$ \\
\hline $\mathrm{N}$ person years & 274419 & 545011 & 583256 & 495696 & 323049 & 2395724 \\
\hline
\end{tabular}

* $\mathrm{p}<0.05 ; * * \mathrm{p}<0.01 ; * * * \mathrm{p}<0.001$

Standard errors were adjusted for the clustering of people in neighbourhoods.

\subsection{Decomposition of ethnic differentials}

The gap between Dutch and ethnic minority groups can be decomposed into two parts. One part of the Dutch-ethnic minority gap can be explained by ethnic differences in the distribution of measured characteristics. Another part cannot be explained and should be attributed to unexplained ethnic differences in processes generating different transition rates into home ownership. This unexplained part may include both ethnic differences in the importance of separate explanatory variables and unmeasured and omitted variables.

Suppose that the probability of home ownership, $H$, is given by the following non-linear equation:

$H=F\left(X_{i} \hat{\beta}\right)$ 
where $X_{i}$ is a vector of explanatory variables for individual $i$ and $\beta$ is a vector of associated coefficient estimates. We quantify the separate contribution of observed variables to native-ethnic minority differences in home ownership using the decomposition method for non-linear equations discussed in Fairlie (1999).

$$
\bar{H}^{D}-\bar{H}^{E_{j}}=\left[\sum_{i=1}^{N^{D}} \frac{\left(X_{i}^{D} \hat{\beta}^{E_{j}}\right)}{N^{D}}-\sum_{i=1}^{N^{E_{j}}} \frac{\left(X_{i}^{E_{j}} \hat{\beta}^{E_{j}}\right)}{N^{E_{j}}}\right]+\left[\sum_{i=1}^{N^{D}} \frac{\left(X_{i}^{D} \hat{\beta}^{D}\right)}{N^{D}}-\sum_{i=1}^{N^{D}} \frac{\left(X_{i}^{D} \hat{\beta}^{E_{j}}\right)}{N^{D}}\right]
$$

Where $N^{D}, N^{E_{j}}$ are the sample size for Dutch and ethnic minority group $j$. The decomposition of ethnic differences is estimated using the Fairlie-decomposition method, specifying the sample of Dutch as the reference group (Fairlie, 1999, 2002). The results of this decomposition analysis are reported in table $3^{1}$.

Table 3. The explained ethnic gap in transition to home ownership

\begin{tabular}{|c|c|c|c|c|c|c|c|c|}
\hline & \multicolumn{2}{|c|}{ Dutch-Moroccan } & \multicolumn{2}{|c|}{ Dutch-Turkish } & \multicolumn{2}{|c|}{ Dutch-Surinamese } & \multicolumn{2}{|c|}{ Dutch-Western } \\
\hline Prob. of home ownership for Dutch & 0.089 & & 0.089 & & 0.089 & & 0.089 & \\
\hline Prob. of home own. for ethnic group & 0.019 & & 0.043 & & 0.056 & & 0.065 & \\
\hline Difference & 0.070 & & 0.046 & & 0.034 & & 0.024 & \\
\hline Total explained & 0.042 & & 0.043 & & 0.035 & & 0.021 & \\
\hline \multirow[t]{2}{*}{ \% explained } & 59.7 & & 92.9 & & 104.3 & & 88.6 & \\
\hline & Coef. & $z$ & Coef. & $z$ & Coef. & $z$ & Coef. & $z$ \\
\hline $\mathrm{d} 1$ & -0.103 & -18.06 & -0.100 & -17.76 & -0.098 & -17.74 & -0.095 & -17.38 \\
\hline $\mathrm{d} 2$ & -0.050 & -16.41 & -0.047 & -15.94 & -0.044 & -15.93 & -0.041 & -15.36 \\
\hline d3 & -0.008 & -10.02 & -0.005 & -7.65 & -0.003 & -5.58 & -0.002 & -3.20 \\
\hline d4 & 0.026 & 18.23 & 0.026 & 17.90 & 0.027 & 17.86 & 0.026 & 17.69 \\
\hline d5 & 0.056 & 16.13 & 0.054 & 15.83 & 0.052 & 15.81 & 0.049 & 15.47 \\
\hline d6 & 0.078 & 16.66 & 0.070 & 16.23 & 0.066 & 16.18 & 0.061 & 15.56 \\
\hline \multicolumn{9}{|l|}{ Individual characteristics } \\
\hline Age & -0.001 & -1.30 & -0.001 & -1.09 & 0.001 & 3.26 & 0.001 & 3.22 \\
\hline Age Squared & -0.014 & -13.91 & -0.012 & -16.54 & -0.005 & -16.95 & -0.005 & -17.68 \\
\hline Woman & 0.000 & -4.92 & 0.000 & -4.93 & -0.001 & -5.05 & 0.000 & -4.98 \\
\hline Education -Extended primary & 0.000 & -0.95 & 0.000 & -1.01 & 0.000 & -1.03 & 0.000 & -0.93 \\
\hline Education -Secondary & 0.001 & 7.46 & 0.001 & 15.89 & -0.002 & -2.17 & -0.002 & -2.20 \\
\hline Education -High & 0.008 & 5.60 & 0.008 & 5.62 & 0.006 & 5.87 & 0.002 & 9.51 \\
\hline Number of children in household & -0.002 & -4.91 & -0.002 & -5.01 & 0.000 & -4.35 & 0.000 & 4.94 \\
\hline Benefit receiver & 0.008 & 32.86 & 0.008 & 33.00 & 0.005 & 33.27 & 0.002 & 27.61 \\
\hline Other labour market position & 0.002 & 4.17 & 0.002 & 4.19 & 0.001 & 4.19 & 0.001 & 4.16 \\
\hline Log earnings & -0.009 & -7.07 & -0.012 & -9.04 & -0.026 & -16.01 & -0.021 & -14.05 \\
\hline Value of home & 0.000 & 5.34 & 0.000 & 5.38 & 0.000 & 5.38 & 0.000 & 5.97 \\
\hline Married / cohabiting & 0.003 & 8.45 & 0.004 & 8.45 & -0.002 & -8.27 & -0.001 & -8.09 \\
\hline Separated / divorced & -0.001 & -9.35 & -0.001 & -10.74 & -0.004 & -11.76 & -0.001 & -10.01 \\
\hline Single to Couple & -0.001 & -10.55 & 0.000 & -0.72 & 0.000 & 10.96 & 0.000 & 9.28 \\
\hline \multicolumn{9}{|l|}{ Parental background } \\
\hline Mother unmarried & -0.001 & -7.47 & -0.001 & -7.43 & 0.003 & 8.26 & 0.000 & 9.90 \\
\hline
\end{tabular}

\footnotetext{
${ }^{1}$ Since sample sizes are not the same for all ethnic groups and the decomposition may be sensitive to sample size (Fairlie 2003), we performed an alternative decomposition exercise. First, we attached the observed characteristics of Dutch people to ethnic minority group j, and calculate the average hazard rate. Subsequently, we did the other way around: we attach the observed characteristics of ethnic minority group $\mathrm{j}$ to Dutch people, and calculate the average hazard rate. This decomposition analysis showed that the size of ethnic gap was pretty similar across decomposition methodologies but the explained part of ethnic gap varies by decomposition methods applied although the pattern of explained gap remains similar for ethnic groups. The results are not presented here but available on request.
} 


\begin{tabular}{lrrrrrrrr} 
Mother benefit receiver & 0.001 & 3.26 & 0.001 & 3.26 & 0.001 & 3.24 & 0.000 & 3.22 \\
Father benefit receiver & 0.001 & 2.88 & 0.001 & 2.88 & 0.000 & 2.87 & 0.000 & -2.76 \\
Father non-participant & 0.001 & 2.79 & 0.002 & 2.79 & 0.001 & 2.78 & 0.001 & 2.79 \\
Mother non-participant & -0.002 & -5.59 & -0.003 & -5.55 & -0.004 & -5.60 & -0.003 & -5.61 \\
Parent(s) owner of home & 0.022 & 31.90 & 0.020 & 30.36 & 0.019 & 35.63 & 0.012 & 33.93 \\
\hline Neighbourhood conditions & & & & & & & & \\
\hline \% non-western migrants & 0.001 & 0.98 & 0.001 & 0.98 & 0.001 & 0.98 & 0.000 & 0.98 \\
\% owner-occupied homes & 0.013 & 19.15 & 0.013 & 18.99 & 0.017 & 19.03 & 0.008 & 18.21 \\
Value of home & -0.002 & -8.44 & -0.002 & -8.39 & -0.003 & -8.41 & -0.001 & -8.05 \\
\% receiving benefits & -0.001 & -1.11 & -0.001 & -1.11 & -0.001 & -1.11 & 0.000 & -1.12 \\
\hline
\end{tabular}

Standard errors were adjusted for clustering in the neighbourhood.

The estimated transition probability to home ownership over the period 1999-2005 is 0.089 for Dutch. This probability is 0.019 for Moroccans, 0.043 for Turks, 0.056 for Surinamese and 0.065 for Western. Accordingly, the ethnic gap in the transition probabilities is $0.07,0.046,0.034$ and 0.024 for Moroccan, Turkish, Surinamese and Western. About 60 percent of the Dutch-Moroccan gap can be explained by the observed characteristics. The explained part of the gap is about 93 percent for Turks and 87 percent for Western. The Dutch-Surinamese gap (0.034 difference in probabilities) can be fully explained by the observed characteristics. The Fairlie-decomposition method even indicates a negative gap, that is a higher hazard of transition to home ownership for Surinamese than Dutch. This suggests that Surinamese would have a slightly higher transition rate than Dutch if they were to have the characteristics of Dutch. The smallest ethnic gap is for Western, about 0.024, which can be almost completely explained by the observed characteristics.

When we look at the contribution of separate variables to the explained differences, a relatively low education and earnings for Moroccan and Turkish people appear to be important factors in explaining the ethnic transition gap as is the low level of parental home ownership. On the other hand, a relatively high rate of married couples among Moroccans and Turks seems to be a favourable characteristic for these ethnic groups to lower the ethnic transition gap.

\subsection{Robustness Checks}

Transition rates have been estimated for those living in rented accommodation based on the implicit assumption that these people have been always tenants. However, we do not have entire tenure histories. If transitions to home ownership were made prior to the start of the observation period for this research, and the relevant pre-period history is related to unobservable characteristics of individuals that cause the transition process in the sample period, then the initial conditions problem arises. Treating initial conditions as exogenous variables can result in biased and inconsistent parameter estimates (Heckman 1981a, 1981b).

Although people in the age group under analysis often experience transitions as being from tenant to ownership, transitions in the reverse direction are also possible. As Feijten (2005) has shown, such transitions are rare, and they occur particularly in connection with divorce or unemployment. Tenure histories can be complicated because own home ownership status of starters in the housing market is closely related to home ownership status of parents and other household members. The first transition to home ownership follows for many individuals some years after leaving parented accommodation to live in a rented accommodation independently, or with others. However, the first independent residence is not necessarily rented accommodation. Some young individuals leave the parental home to live directly in an owner-occupied home, for example after saving while living with their parents, with the help of their parents, or by moving in with an older partner who owns a home. For these individuals, the transition to home ownership has been already realized at the beginning of the observation period. In our analysis, only those individuals who have left the parental home to live in a rented accommodation independently can make a transition to home ownership. Differences in leaving home directly to ownership may be particularly relevant for 
ethnic gap in transition to home ownership, since many Dutch people grow up with homeowner parents who may help them to become owners (Smits and Mulder 2008) while parents of most nonwestern minorities are tenants.

To quantify the home ownership gap in the beginning of the observation period, we estimated logit regressions relying on cross sectional data in 1999 and calculated the ethnic gap in the level of home ownership. Table 4 shows the ethnic gap and major factors explaining this gap in the beginning of the period studied. The estimated home ownership gap is much higher in 1999, compared to the transition rates from rental to owner-occupied housing. The level of home ownership is 64.3 percent for Dutch, only 8.5 percent for Moroccan, 19.7 percent for Turkish, 29.7 percent for Surinamese and 49.6 for Western migrants. About 55 to 58 percent of the ethnic gap is explained for Moroccan and Turkish migrants by their unfavourable socio-economic, household and neighbourhood characteristics. The explained gap is higher for Surinamese and western migrants, being 87 and 78 percent respectively. The high explained ethnic gap, together with ethnicity effect, assures us that our regression models include the most relevant variables that explain a large part of the variation in home ownership.

Table 4. The explained ethnic gap in home ownership: initial situation in 1999

\begin{tabular}{|c|c|c|c|c|c|c|c|}
\hline \multirow[b]{2}{*}{ Prob. of home ownership for Dutch } & \multicolumn{3}{|c|}{ Dutch-Moroccan Dutch-Turkish } & \multicolumn{4}{|c|}{ Dutch-Surinamese Dutch-Western } \\
\hline & 0.643 & & 0.643 & 0.643 & & 0.643 & \\
\hline Prob. of home ownership for ethnic group & 0.085 & & 0.197 & 0.297 & & 0.496 & \\
\hline Difference & 0.558 & & 0.447 & 0.347 & & 0.147 & \\
\hline Total explained & 0.309 & & 0.258 & 0.301 & & 0.114 & \\
\hline$\%$ explained & 55 & & 58 & 87 & & 78 & \\
\hline $\begin{array}{l}\text { Contribution of selected variables } \\
\text { to the explained component }{ }^{\#}\end{array}$ & Coef. & $\mathbf{z}$ & Coef. & Coef. & $\mathbf{z}$ & Coef. & $\mathbf{z}$ \\
\hline Number of children in household & -0.013 & -33.42 & $-0.014-29.20$ & 0.003 & 23.54 & 0.008 & 27.93 \\
\hline Benefit receiver & 0.031 & 36.01 & $0.033 \quad 36.95$ & 0.018 & 38.39 & 0.003 & 39.79 \\
\hline Log earnings & 0.022 & 23.84 & 0.01823 .58 & 0.002 & 10.35 & 0.011 & 21.83 \\
\hline Couple household & -0.018 & -42.71 & $-0.035-45.75$ & 0.033 & 47.98 & 0.015 & 46.02 \\
\hline Parent(s) owner of home & 0.074 & 67.95 & $0.009 \quad 6.41$ & 0.057 & 69.76 & 0.030 & 70.28 \\
\hline$\%$ rental homes in neighbourhood & 0.257 & 104.60 & $0.068 \quad 67.87$ & 0.056 & 69.76 & -0.005 & -19.61 \\
\hline Mean value of homes in neighbourhood & -0.178 & -18.96 & $-0.022-18.96$ & -0.017 & -18.86 & -0.005 & -19.61 \\
\hline$\%$ benefit receivers in neighbourhood & -0.012 & -6.59 & $-0.013 \quad-6.57$ & -0.009 & -6.62 & -0.003 & -6.52 \\
\hline
\end{tabular}

\#Only variables having a coefficient higher than 0.01 are presented

It is likely that a significant part of tenure history is age-specific. People in older ages are in advanced stages of their lifecycle while younger people, who are at the beginning of housing and labour market career, are more likely to be at the risk of moving into their first owner-occupied home. In an attempt to reduce the potential effect of initial conditions, we repeat the regression and decomposition exercises while limiting the population to those who were aged 23 to 27 years in 1999 . In our data this age group was the least likely to be living in an owner-occupied home in 1999. Correspondingly, this population is likely to be at the beginning of transition process and the initial condition problem is probably less relevant.

Table 5 presents the decomposition estimates for the age cohorts 23 to 27 . The estimated ethnic gap in transition to home ownership is higher than the estimates relying on age 20-45. It is 50 percent higher for Moroccan ( 0.126 versus 0.07 ) and more than double for other migrant groups: 0.095 versus 0.046 percent for Turkish, 0.072 versus 0.034 percent for Surinamese and 0.052 versus 0.024 percent for Western migrants. These high ethnic gaps are unsurprising given the low level of home ownership for immigrants in the beginning of the analysis period. The high ethnic gaps for this young population also suggest that transition to home ownership occurs at relatively advanced ages for migrant groups. The explained part of the ethnic gap is a little lower than that in the 
decomposition analysis in Table 3. The ethnic gap is largely explained by a relatively low proportion of higher educated people and a drastically low level of home ownership among the parents of migrants, as reported in Table 3. Interestingly, the ethnic gap in the transition for Surinamese and western migrants is significantly compensated by their higher earnings, while other characteristics are constant. The low level of parental home ownership reflects the degree of intergenerational wealth accumulation which is associated with the migration history of these groups. Many Mediterranean migrants arrived in the Netherlands in the 1960s and 1970s with their intention being to return to their home country within a couple of years. Dutch society was also a threat to them as temporary migrants. From the second half of 1980 s onwards, their orientation has increasingly shifted towards the Netherlands. For many immigrants, therefore, home ownership in the Netherlands has been a serious investment option during the last 20 to 25 years. This may explain a large part of ethnic gap for both Turkish and Moroccan migrants. The difference in the unexplained gap for Turkish and Moroccan migrants may, however, stem from differences in attitudes towards home ownership since these two groups are quite similar as regards their socio-economic characteristics and migration histories.

Table 5. The explained ethnic gap in transition to home ownership for those who were 23-27 years old in 1999

\begin{tabular}{|c|c|c|c|c|c|c|c|c|}
\hline & \multicolumn{2}{|c|}{$\begin{array}{l}\text { Dutch- } \\
\text { Moroccan }\end{array}$} & \multicolumn{2}{|c|}{$\begin{array}{l}\text { Dutch- } \\
\text { Turkish }\end{array}$} & \multicolumn{2}{|c|}{$\begin{array}{c}\text { Dutch- } \\
\text { Surinamese }\end{array}$} & \multicolumn{2}{|c|}{$\begin{array}{l}\text { Dutch- } \\
\text { Western }\end{array}$} \\
\hline Prob. of home ownership for Dutch & 0.152 & & 0.152 & & 0.152 & & 0.152 & \\
\hline Prob. of home ownership for ethnic group & 0.026 & & 0.057 & & 0.080 & & 0.010 & \\
\hline Difference & 0.126 & & 0.095 & & 0.072 & & 0.052 & \\
\hline Total explained & 0.090 & & 0.093 & & 0.073 & & 0.045 & \\
\hline$\%$ explained & 51 & & 79 & & 100 & & 80 & \\
\hline $\begin{array}{l}\text { Contribution of selected variables } \\
\text { to the explained component }\end{array}$ & Coef. & $\mathbf{z}$ & Coef. & $\mathbf{z}$ & Coef. & $\mathbf{z}$ & Coef. & z \\
\hline Education -High & 0.017 & 2.57 & 0.017 & 2.58 & 0.012 & 2.62 & 0.005 & 4.21 \\
\hline Log earnings & 0.004 & 1.87 & 0.003 & 1.46 & -0.015 & -7.94 & -0.008 & 4.80 \\
\hline Benefit receiver & 0.008 & 14.06 & 0.010 & 14.47 & 0.006 & 16.14 & 0.001 & 5.75 \\
\hline Parent(s) owner of home & 0.033 & 14.71 & 0.030 & 13.81 & 0.028 & 18.78 & 0.0191 & 16.68 \\
\hline$\%$ rental homes & 0.013 & 10.42 & 0.013 & 10.25 & 0.018 & 10.21 & 0.011 & 8.73 \\
\hline
\end{tabular}

\section{Conclusions}

The dynamic analysis extends the home ownership literature by examining ethnic differentials in the transition to home ownership and by quantifying the contribution of a rich set of individual and contextual variables to the ethnic home ownership gap. The analysis provides new evidence for a low transition rate to home ownership by migrants in the Netherlands, in particular Moroccan and Turkish migrants. A large part of the ethnic gap in home ownership is explained by observed characteristics that are less favourable for migrants. A low home ownership level on the part of parents together with a less favourable socio-economic background has a long-lasting effect on the transition to home ownership of young migrants. Young immigrants appear to move to an owneroccupied home at more advanced ages relative to their Dutch counterparts.

The estimates indicate that the gap in transition to home ownership for Moroccan and Turkish migrants remains after controlling for a large set of observed characteristics. This implies the persistence of the ethnic gap in home ownership for these groups. On the other hand, the observed ethnic gap in transition to home ownership for Surinamese and Western migrants can be entirely explained by their less favourable characteristics. Our best estimates indicate that the mean transition probability is the lowest for Moroccan as 0.019 , for whom the ethnic gap has been quantified as 0.07 . About $60 \%$ of the gap ( 0.042 out of 0.07 ) is explained by the measured 
characteristics. For Turkish migrants who are quite similar to Moroccans regarding their socioeconomic position in the Netherlands, the estimated mean transition probability is 0.043 and the estimated ethnic gap is about 0.046 of which 0.043 is explained by their unfavourable characteristics. For Surinamese and Western migrants, the mean gap is 0.034 and 0.024 respectively. The entire gap for these two groups is explained from their observed characteristics. The decomposition analysis suggests indeed that Surinamese and Western migrants would have had a higher transition rate than Dutch when they had similar characteristics as Dutch. A large part of ethnic gap in home ownership is explained by a small number of observed characteristics. The most influential variable seems to be a low parental home ownership rate among immigrants. The gap is also strongly related to a low education and income level of immigrants and a high dependence on social welfare while high marriage rates among immigrants reduces the gap.

In addition to the explained gap, ethnic origin seems to play an important role in explaining disparities in home ownership. A large unexplained gap for Turkish but especially for Moroccan immigrants confirms our hypothesis which links this unexplained residual to the cultural and linguistic distance of immigrants from Dutch. This residual is clearly very small for culturally similar Surinamese and Western migrants. The estimated differences between ethnic groups indicate the presence of ethnic group specific factors, different than the observed explanatory factors in the current study. In particular, the significant difference in the ethnic home ownership gap for Moroccan and Turkish migrants suggests that, with regard to their socio-economic position in the Netherlands, these comparable groups obviously have a deviating inclination to move to home ownership, either by choice or because of constraints such as discrimination. The finding that this gap is larger for Moroccan migrants than for Turkish migrants raises doubts about the impact of home-country orientation of immigrants on home ownership, since Moroccan migrants are generally seen as less strongly oriented towards their home country, compared to Turkish migrants who are relatively strongly oriented towards Turkey. If home-country orientation of immigrants is positively correlated with investments in the home country, we may conclude that the large unexplained gap for Moroccans is not likely caused by a choice for the home country as a location of investment in home ownership. It also seems unlikely that differences in remittances explain the differences in home ownership between the ethnic categories. From other sources we know that in fact a higher percentage of Surinamese living in the Netherlands contribute to the livelihood of people in the home country through remittances (62\%) than of Turks and Moroccans, and the percentage of Moroccans who do so is higher (47\%), but not spectacularly so, than that of Turks (Schans 2007).

The unexplained component of the gap asks for other (unobserved) factors influencing ethnic disparities in home ownership. The most disadvantaged migrant groups, Moroccans and Turks, have a high job and income insecurity associated with high unemployment, temporary contracts, unskilled occupations and dependence on welfare benefits. Therefore, these migrant groups are likely reluctant to make a long-term investment in home ownership. The large unexplained gap for Moroccans in particular suggests a stronger effect of cultural or religious differences in attitudes towards home ownership or mortgages and discrimination. Moroccan immigrants are more often seen as a problematic category in the sense of integration into the Dutch society, which might lead to greater discrimination problems and/or a lower inclination among Moroccans to commit themselves to home ownership. This study included some robustness checks to ensure the size and composition of the ethnic home ownership gap. These exercises indicated that the estimated ethnic gap is larger when cross-sectional data is used, relative to the ethnic gap in transition rates to home ownership obtained from longitudinal data. These exercises also showed that, while the pattern of the explained gap remained similar among the ethnic groups, the size of ethnic gap is quite considerable when we consider the age group (23-27 year olds) for whom the transition to home ownership is most likely to be their first step in the housing career. This result suggests that insecurity in the labour market is in particular relevant for young immigrants who obviously need a longer time to obtain a secure position in the labour market so that they can buy a house. 


\section{References}

Aalbers, M.B. (2007). What types of neighbourhoods are redlined? Journal of Housing and the Built Environment 22(2): 177-198.

Alba, R. and J. Logan. 1992. Assimilation and Stratification in the Homeownership Patterns of Racial and Ethnic Groups. International Migration Review 26: 1314-41.

Allison, P.D. (1982). Discrete-time methods for the analysis of event histories. In S. Leinhardt (ed.), Sociological Methodology 1982. San Francisco: Jossey-Bass.

Boehm, 1993 Thomas P. Boehm, Income, wealth accumulation, and first-time homeownership: an intertemporal analysis. Journal of Housing Economics, 3 (1993), pp. 16-30

Boehm, T.P. and A.M. Schlottmann. 2004. The Dynamics of Race, Income, and Homeownership. Journal of Urban Economics 55: 113-130.

Boehm, T. P., Schlottmann, A.M. (2009). The Dynamics of Homeownership: Eliminating the Gap Between African American and White Households. Real Estate Economics 37:4, 599-634

CBS, (2005). Webmagazine, Monday 15 August 2005 10:00

Charles, K.K. and E. Hurst. 2002. The Transition to Homeownership and the Black/White Wealth Gap. Review of Economics and Statistics 84(2): 281-297.

Cortes, Alvaro, Herbert, Christopher E., Wilson, Erin, Clay, Elizabeth, 2007. Factors affecting hispanic homeownership: a review of the literature. Cityscape 9, 53-91.

Constant, A. \& R. Roberts \& K.F. Zimmermann (2009). "Ethnic Identity and Immigrant Homeownership. Urban Studies, 46 (9), 1879-1898

Coulson, N. E. and Dalton, M. (2010). Temporal and ethnic decompositions of homeownership rates: Synthetic cohorts across five censuses. Journal of Housing Economics, 19, 155-166

Coulson, Edward, Li, Herman 2013. Measuring the external benefits of homeownership. Journal of Urban Economics 77, 57-67.

Coulson, N. Edward, 1999. Why are Hispanic- and Asian-American homeownership rates so low?: immigration and other factors. Journal of Urban Economics 45 (2), 209-227.

Deng, Yongheng, Ross, Steven L., Wachter, Susan, 2003. Racial differences in homeownership: the effect of residential location. Regional Science and Urban Economics 33 (5), 517-556.

DeSilva, Sanjaya \& Elmelech, Yuval. (2012) Housing Inequality in the United States: Explaining the White-Minority Disparities in Homeownership. Housing Studies, 27, 1, 1-26, DOI: 10.1080/02673037.2012.628641

DiPasquale, Denise, Glaeser, Edward, 1999. Incentives and social capital: are homeowners better citizens? Journal of Urban Economics 45, 354-384.

Dawkins, C. 2005. Racial Gaps in the Transition to First-Time Homeownership: The Role of Residential Location. Journal of Urban Economics 58: 537-54.

Engelhardt, G. and et al. (2010). What Are the Social Benefits of Home Ownership? Experimental Evidence for Low-Income Households, Journal of Urban Economics. 67, 3, 249-258.

Fairlie, Robert W., (1999). The Absence of the African-American Owned Business: An Analysis of the Dynamics of Self-Employment. Journal of Labor Economics, 17, 1, 80-108.

Fairlie, Robert W., 2002. An extension of the Blinder-Oaxaca decomposition technique to logit and probit models. Journal of Economic and Social Measurement 30, 305-316. 
Feijten, Peteke, 2005. Union dissolution, unemployment and moving out of homeownership. European Sociological Review, 21, 1, 59-71.

Gabriel, Stuart, Painter, Gary, 2003. Pathways to homeownership: an analysis of the residential location and homeownership choices of black households in Los Angeles. The Journal of Real Estate Finance and Economics 27, 87-109.

Gabriel, Stuart, Rosenthal, Stuart, 2005. Homeownership in the 1990s: aggregate trends and racial disparities. Journal of Urban Economics 57 (1), 101-127.

Gyourko, Joseph, Linneman, Peter, 1996. Analysis of the changing influences on traditional households' ownership patterns. Journal of Urban Economics 39, 318-341.

Gyourko, Joseph, Linneman, Peter, Wachter, Susan, 1999. Analyzing the relationship between race, wealth and homeownership in America. Journal of Housing Economics 8, 63-89.

Hall, M. and Crowder, K. (2011). Extended-family resources and racial inequality in the transition to homeownership, Social Science Research, 40, 6, 1534-1546

Haurin, Donald, Parcel, T.L., Haurin, R.J., 2002. Does homeownership affect child outcomes? Real Estate Economics 30 (4), 635-666.

Haurin, Donald, Rosenthal, Stuart, 2009. Language, agglomeration, and Hispanic homeownership. Real Estate Economics 37, 155-183.

Heckman, JJ (1981a) Heterogeneity and State Dependence. In S. Rosen (ed). Studies in Labor Markets. Chicago Press, Chicago IL.

Heckman JJ (1981b) The Incidental Parameters Problem and the Problem of Initial Conditions in Estimating a Discrete Time-Discrete Data Stochastic Process. In C.F. Manski and D. McFadden (eds). Structural Analsis of Discrete Data with Econometric Applications, MIT Press, Cambridge, MA, pp. 114-178.

Hilber, Christian, Liu, Yingchun, 2008. Explaining the black-white homeownership gap: the role of own wealth, parental externalities and locational preferences. Journal of Housing Economics $17,152-174$.

Kain, J. and J. Quigley (1972). Housing Market Discrimination, Homeownership, and Saving Behavior, American Economic Review, 62, 263-277.

Krivo, L. J. (1995). Immigrant characteristics and Hispanic-Anglo housing inequality. Demography 32 (4), 599-615.

Kullberg, J., M. Vervoort en J. Dagevos (2009). Goede buren kun je niet kopen. Over de woonconcentratie en woonpositie van niet-westerse allochtonen in Nederland. Den Haag (SCP).

Lancaster, T. (1990). Econometric analysis of transition data. Cambridge University Press: 1990

Megbolugbe, Isaac, Cho, Man, 1996. Racial and ethnic differences in housing demand: an econometric investigation. Journal of Real Estate Finance and Economics 12, 295-318.

Mulder, Clara H., and Wagner, Michael, 1998. First-time home-ownership in the family life course: A West German-Dutch comparison. Urban Studies 35 (4), 687-713.

Myers, Dowell, Megbolugbe, Isaac, Lee, S.W., 1998. Cohort estimation of homeownership attainment among native-born and immigrant populations. Journal of Housing Research 9 (2), 237-269.

Painter, Gary, Yang, Lihong, Yu, Zhou, 2003. Heterogeneity in Asian American homeownership: the impact of household endowments and immigrant status. Urban Studies, 40 (3), 505-530. 
Painter, Gary, Yang, Lihong, Yu, Zhou, 2004. Homeownership determinants for Chinese Americans: assimilation, ethnic concentration, and nativity. Real Estate Economics 32 (3), 509-539.

Schans, Djamila, 2007. Ethnic diversity in intergenerational solidarity. Dissertation University of Utrecht.

Sinning, M 2009, Homeownership and economic performance of immigrants in Germany, Urban Studies, 47, pp. 387-409.

Smits, Annika W. M., \& Mulder, Clara H. (2008). Family dynamics and first-time homeownership. Housing Studies, 23(6), 917-933.

Wachter, S.M., Megbolugbe, I.F. 1992. Racial and ethnic disparities in homeownership. Housing Policy Debate 3, 2, 353-370.

Whitehead, Christine M. E. and Scanlon, Kathleen (2007) Social housing in Europe. In: Whitehead, Christine M. E. and Scanlon, Kathleen, (eds.) Social housing in Europe. LSE London, London, pp. 8-33.

Yu, Zhou, 2006. A different path to homeownership: the case of Taiwanese immigrants in Los Angeles. Housing Studies 21, 555-584.

Zorlu, A. and Hartog, J. (2012). Employment assimilation of immigrants in the Netherlands: dip-andcatch-up by source country. International Journal of Population Research

Zorlu, A. (2013) Occupational Adjustment of Immigrants in The Netherlands. Migration \& Integration, 14:711-731. DOI 10.1007/s12134-012-0264-2 